\title{
Thymoma Presenting as a Giant Intrathoracic Mass
}

\author{
R HASAN $^{\mathrm{a}}$, OS KHAN ${ }^{\mathrm{b}}$, SA NAHIAN ${ }^{\mathrm{c}}$, M AFTABUDDIN ${ }^{\mathrm{d}}$, AB ADHIKARY ${ }^{\mathrm{e}}$
}

\section{Summary:}

Thymoma is an epithelial neoplasm of the thymus, which commonly lies in the anterior mediastinum. Thymomas comprise about $1 \%$ of all mediastinal tumours. The current treatment of invasive thymoma is often multidisciplinary. This report presents a case of giant thymoma arising in the anterior mediastinum.

Surgical resection was scheduled based on the radiological and fine needle aspiration cytology findings. The tumor

\section{Introduction:}

Thymomas are epithelial neoplasm of the thymus. The overall incidence of thymoma is rare, which approximately 0.15 cases per 100,000 of the population per year ${ }^{1}$. Thymoma account for about 20 percent of mediastinal neoplasm. Localization of thymoma resembles that of thymus itself with $75 \%$ of thymoma originating in anterior mediastinum, $15 \%$ originating in both anterior and superior mediastinum, $6 \%$ originating in the superior mediastinum.Other $4 \%$ occur ectopically ${ }^{2}$. In general, thymomas are indolent tumors with local recurrence rather than metastasis. Thymic carcinomas, however, are typically invasive, with high risk of relapse and death ${ }^{3,4}$. Most thymomas patients are between 40 to 60 years of age, and there is slight male predominance. Invasive thymomas and thymic carcinomas are relatively rare tumors, which together represent about $0.2-1.5 \%$ of all malignancies ${ }^{5}$. The major

a. Prof. Rakibul Hasan, Syed- Al Nahian, Department of Cardiac Surgery, BSMMU.

b. Dr. Omar Sadeque Khan, Medical Officer, Department of Cardiac Surgery, BSMMU.

c. Dr. SA Nahian, Department of Cardiac Surgery, BSMMU

d. Dr. Mohammad Aftabuddin, Department of Cardiac Surgery, BSMMU

e. Prof. Asit Baran Adhikary, Professor, Department of Cardiac Surgery, BSMMU.

Address of Correspondence: Professor Dr. Md. Aftabuddin, Chairman, Department of Cardiac Surgery, Bangabandhu Sheikh Mujib Medical University, D-Block, Room no-1203. Mobile+880-1711-677713, E-mail: aftab12uddin@yahoo.com

Received: 4 May, 2014

Accepted: 6 December, 2015 was completely resected. The weight of the tumor was 2000g. The tumor was histologically diagnosed to type B1 thymoma. Patient was discharged from hospital with advice to attend the oncology department for next treatment.

Keywords: Intrathoracic mass, Giant thymoma, Type B1 thymoma.

(J Banagladesh Coll Phys Surg 2016; 34: 37-41)

histological classifications of thymoma by World Health Organization $^{6}$ is: A-Medullary, AB-Mixed type, B1Predominant cortical, B2-Cortical, B3-Well differentiated thymic carcinoma, C-Undifferentiated carcinoma.

Symptoms from thymoma or thymic carcinoma may be due to the presence of a tumor in the mediastinum or may be a manifestation of a paraneoplastic syndrome. Clinical signs and symptoms are related to the size of the tumor and its effects on adjacent organs (eg, chest pain, shortness of breath, cough, phrenic nerve palsy, Superior vana cava obstruction). Pleural or pericardial effusion are the most common manifestations of metastatic involvement. Exatrathoracic metastases occur in less than $7 \%$ of patients ${ }^{7}$.

Thymomas are associated with a wide variety of paraneoplastic disorders, the most common of which is myasthenia gravis. These syndromes are seen in 50 to 60 percent of patients, and more than one syndromes may be present ${ }^{8}$. Upto one-half of thymomas are diagnosed incidentally, based upon a radiographic abnormality in an asymptomatic patient ${ }^{9}$.

Although surgery is the most effective treatment modality for thymomas. In some cases, it is difficult to excise due to involvement of surrounding organs or tumor size. This report presents a case of thymoma that presented as a giant intrathoracic tumor, histologically diagnosed as type B1 thymoma.

\section{Case presentation:}

A 52-year-old male presented with left sided chest pain , breathlessness and weakness in both upper limb. 
Thorough clinical examinations and laboratory tests were done according to symptoms and history. In the examination of motor system, muscle tone and power were reduced where as bulk was normal in both upper limbs. On chest examination breath sound diminished on left side and other examinations revealed normal. Antiacetylcholine receptor antibody level $1 \$ 79 \mathrm{nmol} / \mathrm{L}$. Other laboratory data were normal. Chest X-RAY P/A view shows a large soft globular opacity was seen in left mid and lower zone, perihilar and pericardial region, suggestive of anterior mediastinal mass of chest(Figure1). Chest Computed tomography revealed a sizable welldelineated soft tissue mass $(10.4 \times 8.1 \mathrm{~cm})$ was seen at anterior to ascending aorta and pulmonary trunk, extended downward along the aortic arch down till left hilum(Figure-2). This soft tissue mass shows inhomogeneous enhancement after contrast administration. A Computed tomography guided fine needle aspiration cytology revealed moderate cellular material containing a good number of epithelial cells and a moderate number of lymphocytes of different size with some histiocytes in the background of blood.No malignant cell was seen. An intrathoracic benign tumor was suspected, therefore surgical resection was decided and performed. Surgical access to the mass was

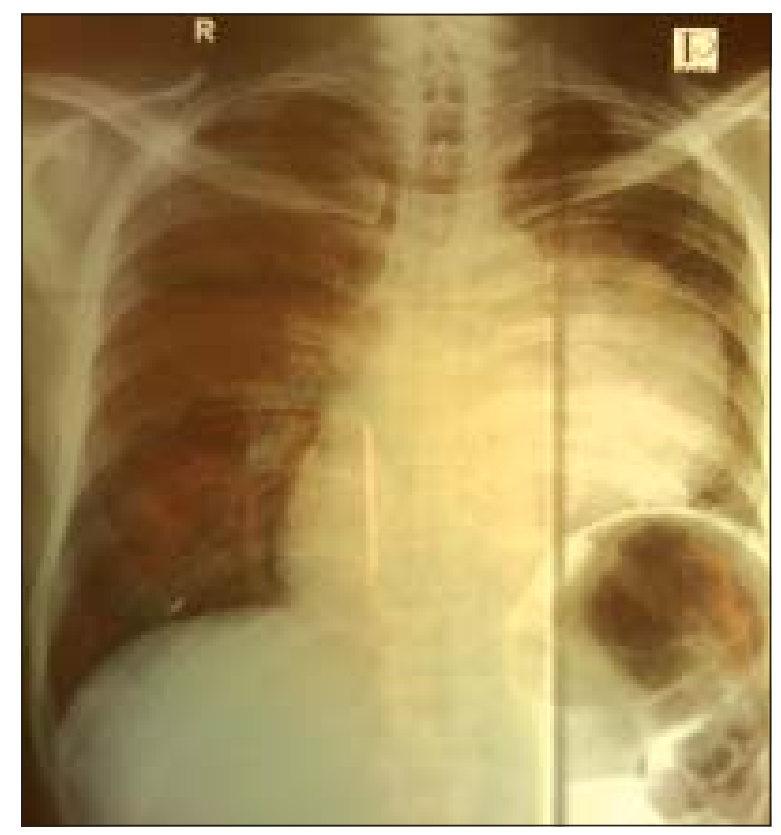

Fig.-1: Chest $x$-ray P/A view shows anterior mediastinal mass of chest with left phrenic nerve palsy.

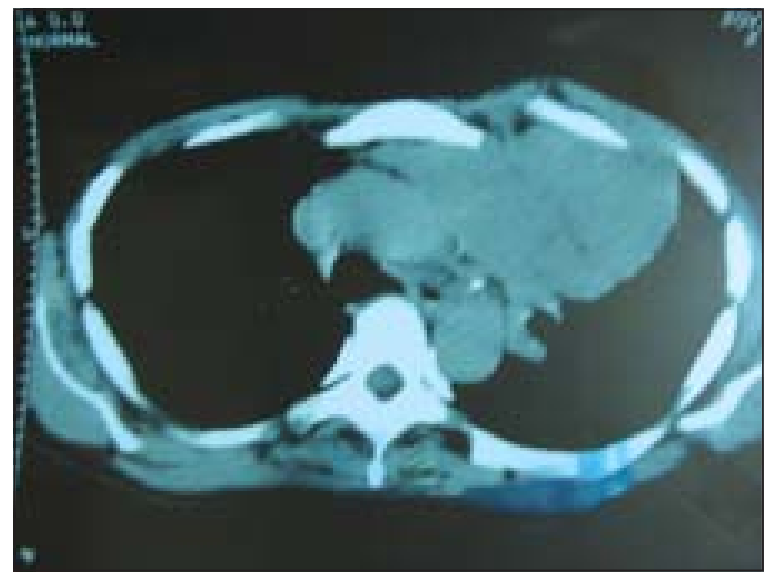

Fig.-2: Computed Tomography scan shows lobulated mass in the anterior mediastinum.

accomplished through a vertical midline incision beginning from sternal notch and extended to the xiphoid with median sternotomy, had some adhesion to the pericardium,pleura of both lungs and left lung. A welldefined giant mass measuring $10 \times 12 \times 8 \mathrm{~cm}$ was found in the mediastinum and left thoracic cavity. The tumor was completely resected without combined resection of the other organs. Some broncho-pleural fistula developed and repaired accordingly. The weight of the tumor was $2000 \mathrm{~g}$. On gross examination it was a well encapsulated mass, outer surface was bosselated. The cut surface of tumor revealed mostly white and partly brownish. Histopathological examination showed a benign tumor composed of densely packed population of small lymphocytes giving rise to starry-sky appearance. Pale areas of medullary differentiation are seen. The neoplastic epithelial cells having pale round to oval nuclei with occasional small nucleoli are also present dispersely. These histopathological findings indicated that the tumor was a type B1 thymoma according to the World Health Organization classification. The postoperative course was uneventful (postoperative management up to discharge ). Then patient was referred to oncology department to Dhaka Medical College Hospital for next treatment.

\section{Discussion:}

Approximately half of all thymomas never produce symptoms, and are discovered incidentally, either on a routine chest X-RAY or at autopsy ${ }^{9}$.Our patient had anterior mediastinal mass on chest X-RAY. In large retrospective study, approximately $47 \%$ of thymoma 
cases (excluding thymic carcinoma)were found to be associated with myasthenia gravis ${ }^{10}$.This is manifestated by the presence of measurable antibodies to acetylcholine receptors as demonstrated in our patient. The symptoms of myasthenia gravis usually precede the discovery of a thymoma. Reports indicate the association of myasthenia gravis with thymoma to be about $15 \%$ but increase to $35 \%$ in older patients ${ }^{11}$.Our patient 52 years old male presented with left sided chest pain. Ocular symptoms like diplopia and ptosis are the commonest clinical presentations in myasthenia gravis seen in more than $50 \%$ of patients ${ }^{12}$. In this case there was no such features.

Thymomas develop in the thymus and are usually located in the anterior mediastinum, only $4 \%$ of the tumors are ectopic tumors ${ }^{13}$. Thymus develops from the ventral portion of the third and fourth pharyngeal pouches and then descends into the anterior mediastinum by the sixth week of gestation. Thymic ectopia results from failure of this migration ${ }^{14}$. Ectopic thymomas have been reported in the neck, middle or posterior mediastinum, lung and pleura, a few reports have described giant intrathoracic tumors ${ }^{15}$. In this case thymus was situated in the normal place (intra-thoracic).

As we suspected this as a case of thymic growth on Xray, we undertook various imaging procedures, among which, Computed Tomography scan was more informative. Keen and Libshitz reported that the presence or absence of intervening fat planes on Computed Tomography accurately predicts vascular and/ or pericardial invasion ${ }^{14}$. However, Fon GT et al. reported that although the presence of preserved fat planes between a thymoma and the adjacent vascular structures reliably excludes macroscopic invasion, the absence of such fat does not consistently indicate an invasive tumor $^{16}$.In this case we performed chest Computed Tomography scan which revealed well delineated soft tissue mass seen at anterior to ascending aorta and pulmonary trunk, extended downward along the aortic arch down till left hilum .

Although the oncological prognosis of thymoma is reported to be more favorable in patients with myasthenia gravis than in patients without myasthenia gravis $^{17}$. Treatment with thymectomy may not significantly improve the course of thymoma associated myasthenia gravis ${ }^{18}$. Standerd primary treatment for these types of tumors is surgical with enbloc resection for invasive tumors, if possible. This report suggest our line of management ${ }^{19,20}$. Thymoma and thymic carcinoma should be differentiated from a number of nonepithelial thymic neoplasm, including neuroendocrine tumors, germ cell tumors, lymphomas,sromal tumors, tumor like lesions(such as true thymic hyperplasia),thymic cysts, metastatic tumors and lung cancer ${ }^{21}$. In our case after thymectomy we send for histopathology. Findings indicating the tumor was type B1 thymoma. Depending on tumor stage, multimodality treatment includes the use of radiation therapy and chemotherapy with or without surgery ${ }^{22,23}$. After surgery we referred our case to oncology department to Dhaka Medical College Hospital for further management. Thymoma has been associated with an increased risk of second malignancies, which appears to be unrelated to thymectomy, radiation therapy, or a clinical history of myasthenia gravis ${ }^{24,25}$. In this case we decided to follow up the patient at regular interval to rule out second malignancies.

The widely accepted staging system is use for thymoma is that proposed by Masaoka et al. based on a postoperative staging procedure, since capsular invasion, a key staging system, is best evaluated by pathologic examination ${ }^{26}$. Recently, the World Health Organization classification of thymic tumours ${ }^{27}$ based on the histological assessment of the morphology of the neoplastic epithelial cells has received increasing acceptance, and it has been shown to be of prognostic significance ${ }^{28,29}$. Thymomas are classified as type A, $\mathrm{AB}, \mathrm{B}$ and $\mathrm{C}$ in the World Health Organization classification, and exhibit organotypic (thymus-like) architectural features.

Nevertheless, the prognostic relevance among type B thymoma subtypes is still controversial. They did not find any significant differences in the incidence of recurrence and survival among the three subtypes of type $\mathrm{B}$ thymomas ${ }^{30}$. The tumor was diagnosed to be type B1 thymoma according to the World Health Organization classification.

The presence of myasthenia gravis in patients with thymoma had been regarded as an indicator of poor prognosis, recent evidence suggests that this is not the case There are reports of improved survival rates for patients with myasthenia gravis with thymoma ${ }^{31}$. 
Indeed prognosis may be improved because thymomas are diagnosed at an earlier stage. In addition, the recurrence rate of patients with myasthenic thymoma is lower than that of patients with nonmyasthenic thymoma ${ }^{32}$.

Although thymomas can present as huge masses, the symptoms and stage may not always correlate with tumor size. A large tumor size is a significantly poor prognostic factor of thymomas ${ }^{33}$. Limmer et al. reviewed previously reported giant thymomas ${ }^{34}$. Interestingly, although a large tumor size is a poor prognostic factor, the resected giant thymomas tended to be low-grade thymomas.

\section{Conclusion:}

This report presented a very rare case of an intrathoracic giant thymoma, histologically diagnosed as type B1. Extended thymectomy followed by radiotherapy must be considered in this type of lesion.

\section{References:}

1. Wright CD . Management of thymomas. Crit Rev Oncol Hematol 2008;65: 109-120.

2. Rosai J, Levine GD. Tumors of the Thymus. Atlas of tumor pathology.2nd ed. Washington, DC: Armed Forces Institute of Pathology ;1975.

3. Ogawa K, Toita T, Uno T. Treatment and prognosis of thymic carcinoma: a retrospective analysis of 40 cases. Cancer 2002;94:3115-3119.

4. Blumberg D, Burt ME, Bains MS. Thymic carcinoma: current staging does not predict prognosis. J Thorac Cardiovasc Surg 1998; 115 : 303-308.

5. Travis WD, Brambilla E, Muller-Hermelink HK, Harris CC. Pathology \&genetics: Tumours of the lung, pleura, thymus and heart. In: World Health Organization Classification of tumours. IARC Press, Lyon, 2004.

6. Masaoka A .Staging system of thymoma. J Thorac oncol 2010; 5 : 304 -312.

7. Lewis JE, Wick MR, Scheithauer BW. Thymoma: A Clinicopathologic Review. Cancer 1987; 60 :2727-2729.

8. Azad MAK, Arafat SM, Islam MA, Quader M, Abdullah ABM.Thymic Carcinoma: A Rare Cause Of SVC Obstruction. Bangladesh J Medicine 2010; 21 : 105-107.

9. Sachiko F, Tomio Y, Rieko M, Kohji M, Keisuke I, Shigeki N. Intracaval and Intracardiac Extension of Malignant Thymoma. Internal Medicine1993;32: 257-260.

10. Okumura M, Ohta M, Tateyama H. The World Health Organization histologic classification system reflects the oncologic behavior of thymoma: a clinical study of 273 patients. Cancer 2002; 94 : 624- 632.
11. Rosenow EC, Hurley BT. Disorders of the thymus: a review. Arch Intern Med 1984; 144:763-770.

12. Drachman DB. Myasthenia gravis. N Engl J Med 1994; 330:1797-1810.

13. Detterbeck FC, Parsons AM. Thymic tumors. Ann Thorac Surg $2004 ; 77$ : 1860-1869.

14. Keen SJ, Libshitz HI. Thymic lesions: experience with computed tomography in 24 patients. Cancer 1987; 59: 1520-1521.

15. Yamazaki K, Yoshino I, Oba T, Yohena T, Kameyama T, Tagawa $\mathrm{T}$ et al. Ectopic pleural thymoma presenting as a giant mass in the thoracic cavity. Ann Thorac Surg 2007, 83:315-317.

16. Chiou GT, Chen CL, Wei J, Hwang WS. Reconstruction of superior vena cava in invasive thymoma. Chest 1990; 97: 502-504.

17. Cameron RB, Loehrer PJ, Thomas CR. Neoplasms of the mediastinum. In: DeVita VT, Hellman S, Rosenberg SA. Cancer: Principles and Practice of Oncology. 7th ed. Philadelphia, Pa: Lippincott Williams \& Wilkins, 2005; 845-858.

18. Budde JM, Morris CD, Gal AA. Predictors of outcome in thymectomy for myasthenia gravis. Ann Thorac Surg 2001; 72 : 197-202.

19. Schmidt-Wolf IG, Rockstroh JK, Schüller Hl. Malignant thymoma: current status of classification and multimodality treatment. Ann Hematol 2003; 82: 69-76.

20. Moore KH, McKenzie PR, Kennedy CW. Thymoma: trends over time. Ann Thorac Surg 2001; 72 : 203-207.

21. Rosai J. Histological Typing of Tumours of the Thymus. New York, NY: Springer-Verlag, 2nd ed. 1999; 31-33.

22. Ogawa K, Uno T, Toita T. Postoperative radiotherapy for patients with completely resected thymoma: a multiinstitutional, retrospective review of 103 patients. Cancer 2002; 94 : 1405-1413.

23. Schmidt-Wolf IG, Rockstroh JK, Schüller Hl. Malignant thymoma: current status of classification and multimodality treatment. Ann Hematol 2003; 82: 69-76.

24. Pan CC, Chen PC, Wang LS. Thymoma is associated with an increased risk of second malignancy. Cancer 2001; 92 : 2406-2411.

25. Engels EA, Pfeiffer RM. Malignant thymoma in the United States: demographic patterns in incidence and associations with subsequent malignancies. Int J Cancer 2003; 4: 546-551.

26. Masaoka A, Monden Y, Nakahara K, Tanioka T. Followup study of thymoma with special reference to their clinical stages.Cancer 1981 ; 48: 2485-2492.

27. Rosai J, Sobin, L. Histological typing of tumours of the thymus, in: World Health Organization. International 
histological classification of tumours. Berlin Heidelberg:Springer,1999; 1-16.

28. Chen G, Marx A, Wen-Hu C, Yong J, Puppe B, Stroebel P et al. New WHO histologic classification predicts prognosis of thymic epithelial tumors:A clinicopathologic study of 200 thymoma cases from China. Cancer 2002;95: 420-429.

29. Kondo K, Yoshizawa K, Tsuyuguchi M, Kimura S, Sumitomo M, Morita J et al. WHO histologic classification is a prognostic indicator in thymoma. Ann Thorac Surg 2004; 77:1183-1188.

30. Kim HK, Choi YS, Kim J, Shim YM, Han J, Kim K. Type B thymoma: Is prognosis predicted only by World Health Organization classification. J Thorac Cardiovasc Surg 2010;139:1431-1435.
31. Monden Y, Nakahara K, Lioka S, Nanjo S, Ohno K, Fujii $\mathrm{Y}$ et al. Recurrence of thymoma: clinicopathological features, therapy, and prognosis. Ann Thorac Surg 1985; 39:165-169.

32. Verley JM, Hollmann KH. Thymoma: a comparative study of clinical stages, histologic features, and survival in 200 cases. Cancer 1985; 55:1074-1086.

33. Wright CD, Wain JC, Wong DR, Donahue DM, Gaissert HA, Grillo HC et al. Predictors of recurrence in thymic tumors: importance of invasion, World Health Organization histology, and size. J Thorac Cardiovasc Surg 2005, 130:1413-1421.

34. Limmer S, Merz H, Kujath P. Giant thymoma in the anterior-inferior mediastinum. Interact Cardiovasc Thorac Surg 2010, 10:451-453. 